\title{
THE EMERGENCE OF POSTCYCLIC PROSODY IN LOANWORD INTEGRATION: TONELESS LATINATE ADJECTIVES IN SERBO-CROATIAN*
}

\author{
MARKO SIMONOVIĆ \\ Utrecht Institute of Linguistics OTS (UiL OTS) \\ Utrecht University \\ Trans 10 \\ 3512 JK Utrecht \\ The Netherlands \\ m.simonovic@uu.nl
}

Abstract: A case of exceptional assignment of prosody to loanwords is considered. In SerboCroatian, where in loanwords the original position of stress is generally preserved in some way, a small class of Latinate adjectives (e.g., ëlementārna 'elementary' and përsonālna 'personal') become toneless and they display the postcyclic initial falling accent. An account of these data is proposed which combines a new approach to postcyclic prosody, which is shown to go hand in hand with syntactically opaque structures, and a new model of loanword integration, which views the loanword trajectory as lexicalisation. As a result, an enriched theory of both domains and their interaction arises to account for the data and shed some additional light on the position of loanwords in the architecture of the grammar/lexicon.

Keywords: loanword integration, postcyclic prosody, prosody/syntax interface, morphology, lexicon

The goal of this paper is twofold. On the empirical side, the goal is to extend the discussion of loanwords to a rarely discussed type of data- the Latinate stratum of the lexicon, of the type which is present in many European languages which have long been (indirectly) influenced by Latin

* Many thanks go to my PhD project supervisors René Kager and Wim Zonneveld, to Boban Arsenijević, the audience of SinFonIJA 4, as well as two anonymous reviewers for all the invaluable interactions and intra-actions. I am also grateful to Nikica Strižak, Sandra Karaulić, Lidija Levkov, Boris Jeločnik, Iva Čukić and Emil Ranc for sharing their native-speaker intuitions with me both on existing and nonce words. All the remaining mistakes are mine. 
(e.g., Slavic and Germanic). These languages have not only developed a substantial number of Latinate lexical items but also "families" of related items (of the type perceptive-perceive-perception in English and perceptivna-percipirati-percepcija in Serbo-Croatian). On the theoretical side, a model of loanword integration will be presented which goes beyond purely phonological adaptations and views loanwords from the perspective of the lexicon (and, consequently, borrowing as a type of lexicalisation). I will show how the emergent model can be put to use to account for the cases of borrowing where morphosyntactic structure matters.

The specific empirical focus of this article is the prosody of the Latinate adjectives in Serbo-Croatian (henceforth SC), more specifically the class of Latinate adjectives which have acquired postcyclic, initial stress/tone, preserving no traces of the original stress whatsoever, e.g., përsonālna and ëlementārna (pErsonaalna and Elementaarna in the notation used in this article). ${ }^{1}$ These adjectives are in a stark contrast to the rest of the SC Latinate words, where the original stress generally does play a role in the assignment of prosodic prominence-compare, for instance, the related nouns persOOnA and elemEnt-but also to the related adjectives in other Slavic languages, e.g., Slovene perso'nalna, elemen'tarna and Russian perso'nal'naja, elemen'tarnaja.

In order to provide a full account of the data, independently justified tools from two linguistic domains will be used. First, an explicit model of loanword integration will be established, which views loanword integration as integration into the lexicon, using a single surface form as its input and producing a whole lexical entry as its output. In this model, the surface properties of the incoming word and the ways in which these properties are reflected in the resultant paradigm play a crucial role. The driving force behind the integration processes is Lexical Conservatism (Steriade 1997), an independently motivated mechanism that militates against the introduction of new allomorphs. As we will see, Serbo-Croatian adjectives of the type pErsonaalna and Elementaarna provide a case which shows where Lexical Conservatism capitulates in order to satisfy other requirements imposed by the recipient system. This is

${ }^{1}$ The capital letters are used to mark prosodic prominence, which is implemented by stress and tone in Serbo-Croatian. The representations of Serbo-Croatian prosody are discussed further in section 1.1. Throughout the paper, I am using the indefinite feminine forms as the citation form for convenience and for feminism's sake. 
where the analysis extends to the second domain and the prosody-syntax interface and the nature of (postcyclic) prosody in Serbo-Croatian is examined. As we will see, in the realm of the native adjectives, there is ample evidence that postcyclic prosody goes hand in hand with semantic/syntactic opacity. From the interaction between the two fields, an account will arise to account for the data and broaden our understanding of both domains. In SC, Lexical Conservatism can preserve a reflex of the original prosody only if another requirement is satisfied: transparent morphological structure, which is unattainable for the adjectives of the type pErsonaalna and Elementaarna due to the fact that they receive an adjectival suffix (-n-, otherwise used to derive adjectives from nouns) although they already have adjectival stems. The effect of this "tautological" derivational suffix is that the adjectives are relegated to the class of opaque headless compound adjectives which results in the assignment of postcyclic prosody.

The article is structured as follows. Section $\mathbf{1}$ introduces the data on the prosody of the Latinate stratum in Serbo-Croatian. Section 2 presents a model of loanword integration in which the driving force is Lexical Conservatism and illustrates it on data from a related language-Macedonian (2.1). Subsequently, in section $\mathbf{2 . 2}$, the relevant data set presented in section $\mathbf{1}$ will be put in the context of the novel model. In section $\mathbf{3}$ we take a closer look at the nature of postcyclic prosody in native adjectives. Section 4 brings a unification of the two domains and an account of the data in terms of the new model. Section $\mathbf{5}$ concludes this paper and lists the questions for further research.

\section{The prosody of Serbo-Croatian Latinate adjectives}

In order to present the data set relevant for this paper, we need to briefly address the preliminaries of Serbo-Croatian prosody and the SC Latinate stratum.

\subsection{SC prosody}

The traditional view is that there are four "accents" in SC, differentiated by length and contour. 
(1) Traditional diacritics for SC accents ${ }^{2}$ and the notation used here (in brackets) short rising: vòda (vOdA) 'water-nom' short falling: vödu (vOdu) 'water-acc' long rising: túga (tUUgA) 'sorrow' long falling: škôla (škOOla) 'school'

All generative analyses of SC prosody (for a recent overview, see Werle 2009) share a few important assumptions. First, the surface rising accents imply underlying tones on the following syllables, so that vòda (vOdA in the notation used here) is analysed as $/ \operatorname{voda}_{\mathrm{H}} /$. Furthermore, whenever there is an underlying tone that is hosted by a non-initial syllable, it will create a rising span over the originally tone-bearing syllable and the one preceding it (hence vòda/vOdA) and the stress will be located on the left syllable of the span. This, in combination with the general ban on final stress, explains why all non-initial accents are rising (at least in native words), so that a form like ${ }^{*} \operatorname{vod} A$ is excluded. This is also the reason why minimal pairs between rising and falling tones can only occur on initial syllables (e.g., vEčEra 'dinner-nom' vs. vEčera 'have dinner3rd person aorist'). Second, the falling accents, which can only occur on the initial syllable of a word, are the underlying Hs on that syllable, so that $v \ddot{o} d u(v O d u)$ 'water-acc' corresponds to $/ \mathrm{vo}_{\mathrm{H}} \mathrm{du} /$. Finally, the initial falling accent is assigned postcyclically to words that have not acquired a stress/tone in the derivation (Inkelas-Zec 1988; Zec 1999). Consequently, $/ \mathrm{vO}_{\mathrm{H}} \mathrm{du} / \mathrm{corresponds}$ to the toneless /vodu/ on yet a deeper level.

This article will look at SC prosody from the perspective of a loanword model that focuses on surface prominence. It will therefore be crucial to see which syllables are prominent in both the original form and the resultant SC form. For this reason, I shall use the following format to represent SC prosody: capital letters are used to mark all the syllables that get surface prominence (stress and tone) and double vowels to mark long vowels. Note that whereas single capitalised vowels (the falling accent, where tone and stress co-occur) will be encountered on the first syllable (in native words), any two adjacent capitalised syllable nuclei should be interpreted as a rising span with the stress falling on the first syllable

${ }^{2}$ As one of my reviewers correctly points out, from these representations, "it seems that S-Cr has four tones, but it actually has only two (rising and falling) bound up with the length of vowels (a long falling tone can only be initiated on a long vowel, never a short one, and so on)". Although this is true for the native system, we shall see that the situation in loanwords forces us to make important distinctions not only between the long and short falling accents, but also between the initial and non-initial ones. 
of the span. Alternatively, the capital letters can be read as indicators of tone-bearing syllables, whereas the distribution of stress is predictable from that of tone (e.g., tatAtA stands for ta'tAtA, whereas tAtata stands for 'tAtata).

(2) Representations of SC tones used here, preceded by the corresponding underlying structure with marked $\mathrm{Hs}$

$\left(\right.$ tata $_{\mathrm{H}} \mathrm{ta} \rightarrow$ ) tAtAta - short rising span over first and second syllable $\left(\right.$ taata $_{\mathrm{H}} \mathrm{ta} \rightarrow$ ) tAAtAta-long rising span over first and second syllable $\left(\right.$ tatata $_{\mathrm{H}} \rightarrow$ ) tatAtA - short rising span over second and third syllable $\left(\right.$ tataata $_{\mathrm{H}} \rightarrow$ ) tatAAtA - long rising span over second and third syllable (tatata $\rightarrow$ ta tata $^{3} \rightarrow$ ) tAtata - short falling accent on the first syllable (taatata $\rightarrow$ taa $\mathrm{H}_{\mathrm{H}}$ tata $\rightarrow$ ) tAAtata - long falling accent on the first syllable

\subsubsection{Prosody of the Latinate stratum of SC}

As already mentioned, the lexicons of the modern Slavic languages have developed "families" of corresponding nouns, (usually biaspectual) verbs and adjectives of Latinate origin, for instance SC percEpcIja (rising span over the second and third syllables) 'perception', percipIIrAti (rising span over the third and fourth syllables) 'to perceive' and pErceptiivan (falling accent on the first syllable) 'perceptive'. In SC, this stratum has arisen after the period of intense contact with Turkish (which finished during the first half of the 19th century) and it has undoubtedly been based on simultaneous contact with other languages, most prominently German and French (although Italian and Russian have played some role as well). Given the multiple sources of the words, it is striking that the loanwords in this stratum show almost exceptionless regularity when it comes to their prosody.

It is important to note that there are no important differences between the stress of Latinate words in German and the Slavic languages that have free stress systems (e.g., Russian, Bulgarian and Slovene). Throughout the paper, I will use German cognates to show the position

${ }^{3}$ I refer the interested reader who is wondering about rationale behind the assignment of the initial high tone to toneless words to Zec-Zsiga (2010) for a recent account. A reviewer points out that I fail "to distinguish sufficiently between surface falling accents that result from initial underlying tone, and those that result from the absence of underlying tone". I agree that my rendition of the system is downplaying this distinction. The reason for this is that the forms traditionally used to motivate this distinction (aorist, restressing PPs, etc.) are both morphologically circumscribed in ways that make it inapplicable to loanwords and disappearing from the Serbian dialect of SC, from which the data are collected. 
of the original stress. ${ }^{4}$ Since the model of loanword adaptation presented here takes morphology to be crucial for the results of language contact, using German as the source language is methodologically relevant. It stands for the fact that SC was never in direct contact with Latin and that the source of, e.g., the verb percipIIrAti is the Latinate German verb perzi'pieren rather than the Latin verb percipio-percipere-percēp $\bar{\imath}-$ perceptum. This is also relevant for the prosody. As we will see, it is crucial that SC elemEnt is related to German Ele ment rather than the Latin word elementum (pronounced as elemEntUm by SC speakers).

In general, Latinate nouns have a prosodic pattern that has a transparent relation to the source stress. Final stress, which, as we have seen in the previous section, is illegal in SC, is resolved by spreading the tone one syllable to the left, which yields a rising span (3b). The same happens in all the other words that do not have an original initial stress (see prOfEsor). It is not surprising that a rising span is the optimal solution here, given the fact that the only SC accents in which prominence (stress and tone) is kept on a single syllable are the falling ones and that falling accents are banned from non-initial syllables. All exceptions to this pattern, which preserve the final stress, end in - nt and have more than two syllables (e.g., elemEnt in (3a)). ${ }^{5}$ What seems to be happening here is that the stressed heavy syllable "arrests" the tonal accent (see 1.2.2 for further discussion of "arresting").

(3) (a) Falling accent replicating the original stress

\begin{tabular}{ll}
\hline SC & German \\
\hline sEnzor & 'Sensor \\
kOlaps & 'Kollaps \\
elemEnt & Ele'ment \\
\hline
\end{tabular}

4 This still does not mean that we are discussing loanwords from German here, since there is ample evidence that Germanic German loanwords are treated differently. An important fact for the present discussion is that Germanic German adjectives remain indeclinable (e.g., feř from German fesch 'nice'), whereas Latinate ones always develop full paradigms (see 1.1.2).

${ }^{5}$ As one of the reviewers notes, the cluster $-n t$ is disrupted in the genitive plural form elemEnaataa, yet the falling accent remains. I interpret this as a paradigm uniformity effect, predicted by the model proposed here (see section $\mathbf{2}$ ) to be very strong in loanwords. 
(b) Rising span replicating the original stress on the second syllable of the span

\begin{tabular}{ll}
\hline SC & German \\
\hline dEkAAn & De'ka:n 'dean' \\
derIvAAt & Deri'va:t \\
kOncErt & Kon'zert \\
prOfEsor & Pro'fessor \\
\hline
\end{tabular}

So far, we have seen the relatively straightforward integration of noun prosody, where the prosody of the SC noun can be predicted from the original form. The same is true of verbs, as can be read off the example percipIIrAti 'perceive', related to German perzi'pieren (-IIrAti corresponds to -ieren throughout SC). ${ }^{6}$ In the next subsection, we are turning to the prosody of the Latinate adjectives, which, as we shall see, is much more involved.

\subsubsection{Latinate adjectives}

All the Latinate adjectives have been integrated by means of the native derivational suffixes $-n$ - (and $-s k$-, more on the suffixes below) - as in the examples we have already seen $p$ Ersonaal- $n$ - $a$ and Elementaar-n- $a$. Two important remarks are in place here, both related to positioning of the Latinate adjectives within the SC lexicon. First, these adjectives are the only declinable borrowed adjectives in SC. The adjectives from the preceding contact with Turkish (e.g., taze 'fresh', rahmetli 'late', hairli 'good'), those from the present-day contact with English ( $k u l$ 'cool', fensi 'fancy'), and even those coming from non-Latinate French and German (knap 'tight', lila 'violet', pase 'passé') are all indeclinable. Second, quite expectedly, SC did not have and has not developed a dedicated "integration morpheme" for turning foreign adjectives into native ones. SC rather "recycles" the suffixes which are productively used for deriving adjectives from nouns and, as we shall see in section $\mathbf{3}$, from complex stems.

${ }^{6}$ This is not to say that the tonal accent will only depend on the original stress: given the fact that new words receive paradigms and automatically interact with native morphemes (some of which are accented), in the case of rising spans the span can include either the preceding or the following syllable, sometimes even within the same paradigm, e.g., $d E k A A n$ 'dean-nom', $\operatorname{dek} A A n A$ 'dean-gen'. The point here is that the rising span always includes the syllable stressed in the original form. 
As we will show in the following section, SC actually has two classes of Latinate adjectives, only one of which strictly requires the label "borrowed".

\subsection{Pseudo-Latinate versus genuine Latinate adjectives}

The two classes of adjectives pattern together in two respects: their derivation and their prosody. As for the derivation, the pseudo-Latinate adjectives are derived from nouns present in SC (e.g., stAndArd-n-a from stAndArd, herOIIn-sk-a from herOIIn) using both - $n$ - and -sk- with a distribution that is related to phonological (see 1.3) and semantic factors (see Arsenijević-Simonović, in progress, for the semantic side). The class of genuine Latinate adjectives is derived from stems that do not figure as independent words and these stems only ever take - $n$ - (e.g., Elementaar-n-a).

In their prosody, the Pseudo-Latinate adjectives replicate the stress of the original in a way similar to nouns or verbs (again, stAndArd-n-a copies the stress of stAndArd, as herOIIn-sk-a does from herOIIn). The genuine Latinate adjectives, however, show different patterns: they are either stress-arresting (e.g., dominAntna) or have the postcyclic initial falling accent (Elementaarna). In the following section, examples of adjectives within the two classes will be presented and a rationale behind the distinction will be elaborated.

\subsubsection{Pseudo-Latinate adjectives}

The important feature of all of the adjectives included in this class is that they can be analysed as derived from a noun within SC. Somewhat foreshadowing our loanword integration model, we can say that their representation in the lexicon is tied to the representation of a noun in the same way as the representation of the native adjective prOOzOrska 'pertaining to a window' is tied to that of the noun prOOzOr 'window'. In other words, the Pseudo-Latinate adjectives are not based on a foreign adjective, and in that sense, they are not proper loanwords. However, they do inform our analysis in one important way: $-n$ - and -sk- do not (necessarily) change the prosodic pattern of the stems they are attached to. Examples in (4) show that the prosody of the adjectives derived from foreign nouns by means of the native suffixes $-n$ - and $-s k$ - copies the prosodic pattern of the noun. 


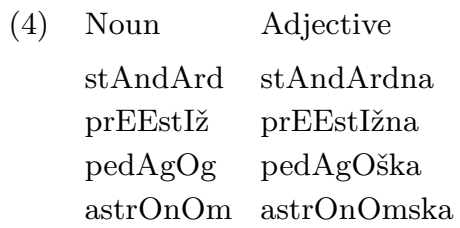

Another group of adjectives belongs to the same class and can be considered a grammaticalised version of the pattern we have just seen. This group comprises adjectives whose stem ends in -ik (French -ique). These adjectives always have a rising span over the $i k$ and the preceding syllable (-ik-always mutates to $-i \check{c}$ - in contact with $-n$ - and $-s k$-).

(5) kOmIčna, sintEtIčka, sinkrEtIčna, terorIstIčka, turIstIčka, urbanIstIčka

Although these adjectives are all borrowed and based on a form ending in - $i k$, the - $i k$ - cannot be analysed as an adjectival suffix in SC because it occurs as often in nouns as it does in adjectives and virtually all adjectives in which it occurs have a related noun in $-i k$ -

(6) Noun sintEtIka statIstIka lOgIka

Adjective sintEtIčka statIstIčka lOgIčna/lOgIčka

Again, the adjectives in this group are not distinct from the native adjectives of the type $m U \check{c}-n-a$ 'painful' derived from $m U k-a$ 'pain' or the adjectives derived from borrowed nouns within SC such as $m U z I c ̌-k-a$ 'musical' derived from mUzIka 'music'.

Having peeled off the pseudo-Latinate adjectives, we can now turn to the class of adjectives that can be considered genuinely Latinate.

\subsubsection{Genuinely Latinate adjectives}

As mentioned above, the adjectives in this class have prosody which, compared to that of the source word, shows a different pattern from the rest of the stratum - one class by being extremely faithful, the other by being extremely unfaithful to the source stress.

The first subclass comprises adjectives whose stem ends in $-t$, most often preceded by another consonant. These adjectives keep the falling tone on the stressed syllable, faithfully to the source throughout the paradigm (as in nouns of the type elemEnt). The examples in (7) show that there probably is a phonotactic conditioning on stress-arresting. The adjectives of this class show hyper-faithful behaviour, with the surface 
prominence not only remaining where it is in the source, but also staying only there (i.e., no rising span is formed).

(7) apstrAktna, dirEktna, dominAntna, arogAntna, apsolUtna, komplEtna

(German ab'strakt, di'rekt, domi'nant, arro'gant, abso'lu:t, kom'plett)

The issue of exact conditioning which plays a role in stress arresting needs further enquiry, which would exceed the scope of this article. However, I would like to make three remarks here, as pointers for further research. First, stress arresting introduces falling accents on non-initial syllables, a structure which most accounts of SC prosody attempt to make unrepresentable/underivable. It does seem that such a structure can only ever surface in SC if sponsored by a foreign input, also given the fact that there are native adjectives with similar structure as apsolUtna and a rising span: e.g., pOdAtna 'happy-go-lucky'. Second, this non-initial falling accent in adjectives always surfaces on short syllables, even in cases where it corresponds to a long syllable in the original (as in apsolUtna vs. German abso'lu:t, cf. also kvalitEtna 'which is of high quality' vs. kvalItEEt '(high) quality'). ${ }^{7}$ Third, in these adjectives, the stress-arresting prosody is preserved even if native derivational suffixes are added: e.g., apstrAktn-ost 'abstractness' and dominAntn-ost 'dominance'. In sum, there seems to be a handshake between the stress of the original and a phonotactically con-

7 The adjectives whose stems do not end in a cluster (illustrated by the last two in (7)) are hard to generalize over, also given the fact that there are examples of structurally equivalent adjectives which take postcyclic prosody: e.g., prIvaatna, corresponding to German pri'va:t. A fact that may be relevant is that $t n$ - is not an attested syllable onset in SC (which seems to be an accidental gap, given the fact that $t l-, t m$ - and $d n$ - are all fine), so that apsolUtna is necessarily syllabified as a.pso.lUt.na.

Furthermore, as one of the reviewers correctly points out, the cluster and the closed syllable do not survive in all the forms, since the indefinite masculine form (which has a null ending) contains an epenthetic a (e.g., apsolUtan, apstrAktan, etc.). Whereas I accept that this might be a problem for my approach, it is important to note that all the other forms in the paradigm (including all the masculine forms, the comparative and superlative forms) lack the epenthetic $a$. Since one of the main features of the approach to loanwords presented here (see section 2) is considering whole recipient language paradigms rather than single forms, I maintain that the feminine forms used here are more suitable to represent the entire paradigms than the "lonely" indefinite masculine forms. Also, I propose that a paradigm uniformity constraint keeps the tone arrested throughout the paradigm.

Acta Linguistica Hungarica 59, 2012 
ditioned tendency for stress-arresting which enables the original stress to be rendered as non-initial falling accent.

Finally, there is a large subclass of genuinely Latinate adjectives that are extremely unfaithful to the source prosody - they all have postcyclic prosody. Although we will in the end provide an account for this class as a whole, traditional approaches would make a distinction between the adjectives derived by means of Latinate suffixes (which we will argue to be no suffixes in SC at all) and the ones that have a simplex source word. The first class then comprises adjectives that contain a Latinate adjectival suffix/sequence -iv-, -ar-/-al-, -oz-, -il-, -or-, -on- or -el-. As we can see in (8), there are no traces of the prosody of the original word or the related nouns. Note that the related nouns are also Latinate, but that this crucially does not mean that they are derivationally related to the adjectives in SC.

$\begin{array}{ll}\text { (8) Latinate nouns and [related adjectives with postlexical stress] } \\ \text { edukAAcIja } & \text { Edukatiivna } \\ \text { dIskUrs } & \text { dIskurziivna } \\ \text { elemEnt } & \text { Elementaarna } \\ \text { skAndAAl } & \text { skAndaloozna } \\ \text { mUzIka } & \text { mUzikaalna } \\ \text { inicIjAAl } & \text { Inicijaalna } \\ \text { dEbIIl 'imbecile' } & \text { dEbiilna }\end{array}$

The last two examples in (8) show that postcyclic prosody overrides the possible inherited tone of the related noun (cf. the related pseudoLatinate adjective $d E b I I l s k a$, which does copy the prosody of the noun). This pattern is productive: if exposed to nonce words such as Adorabiilna, sErioozna, krUcificijaalna, trIbunaalna ${ }^{8}$ in a written form, SC speakers always produce them with this prosody.

This fact has also been observed in the literature: Rakic (2008) states that -aalna and -aarna are examples of dominant suffixes-ones that enforce initial falling accent. Rakić's analysis is synchronically and descriptively correct, once we assume that these sequences function as suffixes. ${ }^{9}$ However, even if we make this assumption, this does not ac-

${ }^{8}$ A Google search confirms the existence of the first two.

${ }^{9}$ It seems that there are good reasons to ask whether -aalna and -aarna (and all the others, which would then all have the same function, adjectivising, but peculiarly complementary distribution) are suffixes in SC. Note that it is not the case that 
count for the borrowing pattern (i.e., why the original stress is ignored here) or the peculiar fact that these dominant suffixes are Latinate and therefore have a very limited distribution.

It is important to notice that the pattern is extremely regular also with respect to vowel quantity: the final vowel of the adjectival stem is always long, whereas all the other vowels are short. This holds even if the related noun has a different distribution of quantity: e.g., nOOrma 'norm', but nOrmatiivna/*nOOrmatiivna. ${ }^{10}$

The second subclass of genuine Latinate adjectives comprises those that have a simplex adjectival stem (at least from the perspective of SC). These adjectives also have postcyclic prosody, as illustrated by the examples in (9a). Also adjectives that might be considered complex (because their first element occurs in multiple words) have postcyclic prosody (9b).

(9) (a) Analoogna, Intiimna, prIvaatna, stUpiidna, sImultaana, mOdeerna

(b) bIseksuaalna, hOmofoobna, mOnogaamna, pOligaamna, Aseksuaalna

Note that there are no exceptions to the postcyclic pattern in this class, so that also all disyllabic stems have this pattern (cf. footnote 10). The fact that postcyclic prosody is even stronger in words that contain no Latinate "suffixes" strengthens our point that the initial falling accent is not due to specific suffixes, but due to something that unites the two sets and distinguishes them from all the other adjectives.

At this point, we can state the main puzzle of our data set. Here we are leaving aside the stress-arresting adjectives (e.g., interesAntna), recalling that stress-arresting is not specific to adjectives (see elemEnt in (3) above) and seems to arise due to a handshake between phonotactic

they are always added to existing stems (Oraalna does not correspond any other stem) and that they are sometimes added to stems which are modified in ways not attested in other words (sEksuaalna is related to $s E k s$, and kOrporaalna is related to kOrpus).

10 There is one small class of apparent exceptions to the regularity just described. For some speakers, in disyllabic stems the rising span is possible. E.g., $n O r$ mAAlna (but also nOrmaalna), OrAAlna (but also Oraalna), etc. As far as I know, all of these adjectives have a stem ending in -aal. This might be related to the fact that there are many Pseudo-Latinate adjectives of this type (e.g., mEtAAlna from mEtAAl, krIstAAlna form krIstAAL, etc.) This might mean that $-a a l$ is becoming more like $-i k$. The SC pronunciation of the brand Oral B $(\operatorname{Or} A A L b E E)$ seems to point in that direction.

Acta Linguistica Hungarica 59, 2012 
conditioning and faithfulness to a foreign surface form. ${ }^{11}$ Henceforth, we are focusing on accounting for the extreme unfaithfulness, i.e., the emergence of postcyclic prosody, which arises when the native suffix $-n$ - is combined with either a simplex adjectival stem or a stem derived using a Latinate morpheme.

In the following subsection, we are looking at the possibilities of solving the whole issue based on the prosodic generalisations holding in SC.

\subsection{A prosodic account?-Prosodic restrictions on adjectives in - $n$ -}

At first sight, there seems to be a way of explaining the facts just by the existing restrictions in SC: adjectives in $-n$ - never have the pattern that would salvage both the original stress and length (these hypothetical forms would be *origInAAlna and *elemEntAArna). The source forms of these adjectives have stem-final stress, e.g., German origi'na:l and elemen'ta:r and Slovene origi'nalna and elmen'tarna, and it is exactly long oxytonic stems (i.e., stems with the final syllable stressed) that have prosody which does not combine well with $-n-$. When $-n$ - is added to such stems, postcyclic prosody results. This can be confirmed from the alternations in the few adjectives derived from nouns with long oxytonic stems in (10); note that all the unproblematic examples come from loanwords.

(10) Noun

abecEEdA 'alphabet'
kultUUrA
propagAAnda
karAktEEr

Adjective

Abeceedna

kUltuurna

prOpagaandna

kArakteerna (in Croatian: karAktEErna)

However, upon closer scrutiny, this explanation falls short. Even for speakers who do not allow combinations such as karAktEErna, the system could have used one of two attested mechanisms to avoid postcyclic prosody:

11 There is another criterion by which the falling tones in the two classes can be shown to be different- the stress of the derived abstract nouns in -ost '-ness'. Whereas the stress-arresting adjectives always keep the stress of the base: apstrAktn-ost 'abstractness', dominAntn-ost 'dominance', postcyclic stress shifts to the penultimate syllable in the majority of cases, e.g., elementAArnOst (from Elementaarna) and originAAlnOst (from Originaalna). 
(a) It could have introduced the faithful forms as a new prosodic type, as it did in the adjectives in (7) (inteligEntna, dirEktna etc.). Note that unlike the adjectives in (7), the obtained forms-e.g., ${ }^{*}$ origInAAlna and ${ }^{*}$ elemEntAArna - would not violate the global prosodic constraints of the language.

(b) It could have shifted the suffix to -sk- (which can combine with oxytonic stems without changing their prosody), as it does for phonological reasons whenever:

- the stem of the base noun ends in - $n$

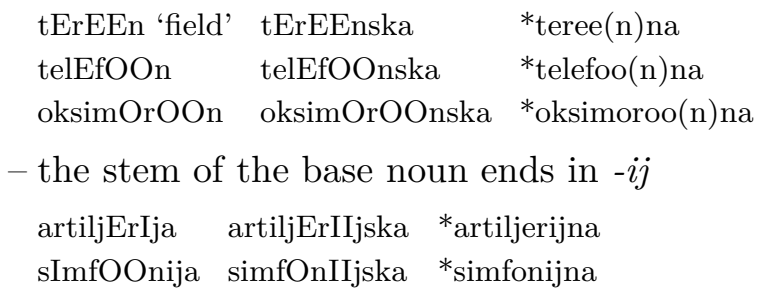

Actually, there are a few cases in which the potential result of the strategy in (b) does surface for other reasons: provincIjAAlska 'provincial' (secondary derivation via the noun provincijAAlAc 'provincial') kulInAArska 'culinary' (secondary derivation via the noun kulInAAr (sic!) 'culinary expert').

Moreover, the alternation between $-n$ - and $-s k$ - just described shows yet another way in which adjectives derived from borrowed adjectival stems (e.g., pErsonaalna, bEniigna) are consistently different from those derived from nouns (stAndArdna, tErEEnska). Whereas the nominal stems ending in $-n$ always receive $-s k$-, the adjectival stems ending in $-n$ receive $-n$-, as illustrated in (11). The sequence $-n n$ - subsequently degeminates to $-n$-, due to the general constraint that militates against geminates. In sum, if the derivation of an adjective goes via a noun ending in $-n$, then its original stress can be preserved (as in telEfOOnska 'pertaining to phone'), whereas if the new adjective gets derived from a foreign adjective, postcyclic prosody emerges.

(11) Endokriina, Androgiina, bEniigna, sImultaana, hOmogeena, pAtogeena (cf. German endo'kri:n, andro'gy:n, simul'ta:n, homo'ge:n, pato'ge:n)

We can conclude that on prosodic grounds only we cannot account for the full set of data. In other words, even if we accept that $-n$ - is not compatible with oxytonic stems, this would just lead to restating the 
question of why $-n$ - and postcyclic prosody is preferred to say $-s k$ - and faithful prosody or innovation in the system. In order to account for the advantage of taking $-n$ - and postcyclic prosody, we need to zoom out and look at the structure of the native adjectives that display this prosodic pattern. But before that, we need a clear theory of what it means for loanwords to integrate into a new lexicon.

\section{The present (emergent) model of loanword integration}

In this section, I present the model of loanword integration, put to use to account for the data set presented in the previous section. The main goal of this model is to move beyond the current discourse on loanwords in formal linguistics, which typically remains focused on strictly phonological "adaptations" (for an overview, see Kang 2011), seen as mappings between the source language forms and the recipient language forms. The goal of the novel model is to let morphology and morpho-syntax enter the picture in order to create an integral theory of borrowing. The model (see also Simonović in progress) is based on the insight that loanword adaptation, unlike most processes observed in grammar, has a (morphologically simplex/unanalysed) surface form from the source language as its input and a full lexical entry in the recipient language (including paradigms and morphosyntactic features) as its output. The integration process starts after a word has been inserted into the recipient language discourse. This initial form is a relentlessly surface form, whose surface properties are then preserved as much as possible throughout the process of lexicalisation. The present model makes use of Lexical Conservatism (motivated by the fact that loanwords start off with a single allomorph) that interacts with the native grammar throughout the process of the lexical entry formation. I give the formulation of Lexical Conservatism used by Steriade (1997) in (12).

(12) The form of lexical conservatism conditions: $\operatorname{Lex}(\mathrm{P})$

Let $\mathrm{T}(\mu)$ be the allomorph of $\mu$ (which stands for morpheme-M.S.) appearing in a form under evaluation.

Let $\mathrm{L}(\mu)$ be a listed allomorph of $\mu$.

Let $\mathrm{P}$ be a phonological property.

$T(\mu)$ is characterized by $\mathrm{P}$ only if some $\mathrm{L}(\mu)$ is characterized by $\mathrm{P}$. 
In order to show a typical case where LC preserves a surface property of the source form, we make a brief excursion to Macedonian, a related language which has no pitch accent system with all its restrictions on distribution of both tone and stress (as well as their co-occurrence) and therefore has the possibility of mimicking French and German stress in a more transparent fashion.

\subsection{Lexical conservatism and Macedonian loanword integration}

Standard Macedonian native words have a regular stress pattern - antepenultimate if the word is trisyllabic or longer, otherwise initial (13a). However, there are quite a few lexically stressed words with either a stressed penult or ult (Hammond 1989). All the words quoted by Hammond are borrowed nouns. These nouns have stem-bound stress as long as the stress remains within the three final syllables, otherwise they follow the native stress pattern $(13 \mathrm{~b}-\mathrm{c})$.

(13) Macedonian masculine nouns

\begin{tabular}{lllll}
\multicolumn{1}{c}{ Bare form } & Definite singular & Definite plural & \\
(a) ódnos & ódnosot & odnósite & 'relation' \\
(b) restorán & restoránot & restoránite & 'restaurant' \\
(c) konzumátor & konzumátorot & $\begin{array}{l}\text { konzumatórite } \\
(\text { *konzumátorite })\end{array}$ & 'consumer'
\end{tabular}

This example allows us to go through the trajectory of borrowing as seen by the present model. The integration trajectory starts with a codeswitch, introducing a word with the non-native stress pattern into the native discourse, which, by virtue of LC, consequently spreads this stress pattern to the rest of the paradigm, as far as undominated constraints of the language allow. At the moment where speakers create a representation in their Macedonian lexicon, the newly introduced items can be treated as the only Macedonian words with a lexical stress. In terms of the Optimality Theory formalism, the LC constraint LEX(STRESS) dominates all the native prosodic constraints which conspire to produce the antepenultimate stress in native words, but not the ones keeping the stress within the trisyllabic window. After the word has been lexicalised and the stress has become part of its representation, the role of LEX(STRESS) is taken over by FAITH. ${ }^{12}$

${ }^{12}$ For readers familiar with OT formalisms, we can say, based on Kager (to appear), that the synchronic ranking is ALIGN-WORD-R $\gg$ FAITHActa Linguistica Hungarica 59, 2012 
Importantly for our specific data set, Macedonian also has Latinate adjectives, some of which show native-like behaviour (e.g., 'direktna, 'stabilna), but many preserve the original stress: Koneski (1976) shows that this is true of almost all adjectives in -ivna (recep'tivna), -alna/-arna (nacio'nalna), -ozna (grandi'ozna) etc. From this we can conclude that there is nothing inherently problematic about LC preserving the prosodic features in adjectives, at least as much as this is allowed in nouns and verbs. Again, SC is clearly different from all the related languages when it comes to this class of adjectives.

\subsection{Lexical conservatism and the SC Latinate stratum}

Viewed from the perspective of the current model, SC Latinate data fall into three categories as far as the preservation of the surface features by LC is concerned. First, the Latinate nouns, verbs, as well as the pseudo-Latinate adjectives, show clear effects of LC in their prosody - the prominent syllable of the source form does receive surface prominence. However, recall that the only accents that keep both tone and stress on the same syllable are the falling ones. Now we see that keeping the prominence only on the syllable stressed in the source form would have led to a violation of native prosodic constraints (the ones militating against falling accents on non-initial syllables). Therefore all the cases of noninitial stress, a span is formed over the source-stressed syllable and the one preceding it, so that German De'ka:n corresponds to SC $d E k A A n$.

The second class comprises the adjectives shown in (7), which are hyper-conservative with respect to the original prosody (e.g., interesAntna) as well as nouns in -nt (e.g., elemEnt). As argued before, the effect of LC interacts with phonotactic conditioning in this case.

Finally, genuine Latinate adjectives (illustrated in (8) and (9)), the ones with a postcyclic prosody, show a total loss of the original prosody, to the detriment of LC - the postcyclic pattern completely overrides both the stress of the original adjective (compare Elementaarna with German elemen'ta:r) and the accent and vowel quantity of possibly related nouns (compare elemEnt with Elementaarna, and hlOOr with hlOrofilna).

Data of this type are important for the model outlined in the previous section because the adjectives in (8) and (9) represent an island

ACCENT $\gg$ PARSE-SYL, HD=TROCHEE, whereas the integration ranking is ALIGN-WORD-R $\gg$ LEX(STRESS) $\gg$ PARSE-SYL, HD=TROCHEE. 
of total capitulation of LC and total prosodic uniformity - a Hungarianlike island in SC. The important question we need to ask is whether the loss of the source prosody can ever be a diagnostic of something and in that sense informative. It can certainly not be informative in terms of the source material. However, as we will see in the following section, SC postcyclic prosody is a diagnostic of morpho-syntactic structure: it generally marks headless complex stems. Thus, in order to give a full account of the data we need to look at the native adjectives with postcyclic prosody.

\section{What does postcyclic prosody stand for? ${ }^{13}$}

There are two large native classes of adjectives with postcyclic prosody. The first class comprises the adjectives derived from nouns which already have postcyclic prosody, e.g., Običaajna 'pertaining to a custom' derived from Običaaj 'custom'. Second, and more interestingly for our purposes, SC has a large class of compound adjectives with the postcyclic pattern. These adjectives have a complex stem preceding the adjectival suffix $-n$.
(a) ljUb-o-moor-n-a 'jealous'
rAt-o-boor-n-a 'pugnacious' love?-connecting vowel-torture?-n-a
war-connecting vowel-fight?-n-a
(b) bEs-prekoor-n-a 'impeccable'
rAvn-o-praav-n-a 'emancipated'
without-reprimand-n-a
straight-connecting vowel-right-n-a

As the tentative glosses in (14) show, the meaning of the compound is not clearly derivable from the meaning of the parts. Also, examples in (14a) show that it can be difficult to determine the meaning of the parts of the complex stem. Moreover, the examples in (14b) illustrate another important generalisation - even if it is possible to identify the morphemes in the stem, there is no straightforward way to express their meaning periphrastically, using the member words. For instance, one cannot say that something or someone is without reprimand (*bez prekora) or that someone has straight rights (*ravna prava). In both cases, other lexemes would be used - bez mane 'without a flaw' and jednaka prava 'equal rights'. In sum, in this large class of compound adjectives postcyclic stress goes hand in hand with semantic opacity/lexicalised meaning. These adjectives are in clear contrast with transparent compound adjectives as jedn-O-gRb-a

\footnotetext{
13 This section is the result of collaboration with Boban Arsenijević on the prosody/ syntax interface in SC.
} 
'one-humped' and crn-O-kOs-a 'black-haired', in which prosodic prominence is aligned with the head (-grb-, related to gRba 'hump' and -kos-, related to $k O s A$ 'hair') as much as the general prosodic constraints allow.

Our account of the connection between postcyclic prosody and semantic opacity is that in opaque compounds syntactic structure is not straightforwardly assigned to the components, or at least not in a way interpretable at the syntax-phonology interface. As a result, no head is recognised and the stem remains headless. For this reason, the prosody of the compound cannot be aligned with (that of) the head and postcyclic prosody is assigned (for a more detailed analysis and other domains in SC showing this effect, see Arsenijević-Simonović in progress).

The compound adjectives are not the only type of adjectives that show a connection between postlexical prosody and semantic/syntactic opacity. There are two more morphemes with idiosyncratic properties that impose postcyclic prosody. First, the obsolete palatalising suffix -uštriggers postcyclic prosody (15a). Second, the element -tvorna 'creating' (related to the obsolete verb tvoriti 'to create') triggers postcyclic prosody (15b). Nonce creations such as kAfotvoorna 'coffee-creating' (from kAfA 'coffee') and mlEkotvoorna (from mlEEkO 'milk') have the same pattern.

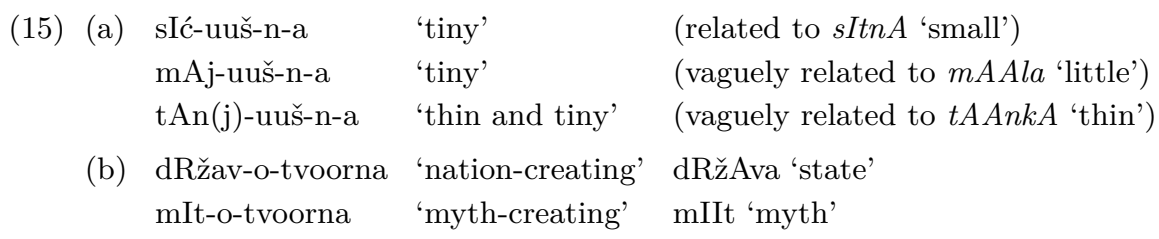

The native data we have seen lead us to a different way of viewing postcyclic prosody in SC: it is a full prosodic template applied to all the opaque/headless units at the syntax/phonology interface. It demarcates the chunk to which it has been applied as a single unit. It is then no wonder that it contains the optimal delimitative solutions within the SC system - it marks the initial syllable with a tone (note that it could not mark the final syllable without having to spread to the syllable preceding it as well) and the final one with length. Note that here I am referring to the length of the final syllable of the stem (e.g., in rAtoboorna 'belligerent'). 


\section{Putting the pieces together: How borrowed adjectives become toneless}

In this section we are using the insights about postcyclic prosody from the previous section to account for its emergence in Latinate adjectives. In order to see how what we have already said contains all the necessary ingredients of an account for our data set, we need to articulate two insights. First, the facts from the previous section can also be viewed from the perspective of the lexicon. What postcyclic prosody means is that the chunk marked by it should be treated as a single domain (in the sense that it serves as a stem), but that it is not an independent element as in the case of, say, nominal stems. Second, as we have seen in section $\mathbf{1}$, adding derivational suffixes to foreign adjectives is a loanword-specific pattern. Native adjectival stems never need to get adjectivised. ${ }^{14}$

Now we can see why borrowed adjectives of the types in (7) (e.g., Elementaarna and Inicijaalna) and (8) (e.g., Uniformna and sImultaana) act as opaque native adjectives. First, adjectives in both (7) and (8) have foreign adjectival stems which receive an extra adjectivising ending $-n$-. This is radically different from the situation within $\mathrm{SC}$, which, quite unsurprisingly, has no adjectives derived from adjectival stems without any added semantic content, a scenario which still makes sense only in loanwords. Upon encountering such adjectives, the grammar is unable to find their stems in the lexicon, and therefore assumes they are opaque/headless at the phonology/syntax interface. Consequently, such adjectives receive postcyclic prosody, just like the opaque native adjectives. Moreover, all adjectives in (7) and those adjectives in (8) which can be analysed as polymorphemic (hOmofoobna), do have complex structures, which are not analysable in native terms, because at least one of their morphemes is unproductive in SC. So, for instance, Elemantaarna includes a foreign language morpheme -aar-which is not productive in the recipient lex-

\footnotetext{
${ }^{14}$ As one of the reviewers notes, the fact that elementa:r is an adjective in German is not a reason to assume that the SC string Elementaar- is an adjectival stem in SC. I agree on this point as far as the synchronic picture of SC is concerned. However, two issues remain. First, it still is a fact that the foreign adjective (and it indeed arrives to the language as an adjective, because it is inserted in an adjectival slot in code-switching), e.g., elementa:r, is integarated using the otherwise adjectivising suffix $-n$-. Second, the status of the stem Elementaar- in $\mathrm{SC}$ remains problematic and this question will be answered by the end of this section.
} 
icon and whose function (adjectivising) is already covered by a native morpheme - $n$-. In sum, its stem has all features of an opaque stem.

In other words, the position of borrowed adjectives is somewhat contradictory when observed from the perspective of the SC lexicon. On the one hand, they already have adjectival meaning and need not be adjectivised in any way. On the other hand, they have no adjectival form and adjectivising suffixes have to be added to them in order to make them full-fledged adjectives. For this reason, they become the kind of stems which cannot be retrieved in the rest of the lexicon and pattern with the other stems which fit this description - the opaque compound (and derived) native stems.

In sum, LC capitulates for a good reason here: in the SC lexicon, encoding of prosodic information of the stem of adjectives in - $n$ - means that these stems can be retrieved. If LC had won, it would have protected an opaque stem.

\section{Conclusions}

The analysis presented here shows how looking at loanwords from the perspective of the recipient lexicon can provide a useful window into the syntax/phonology interface and loanword integration, as well as the interaction between the two domains.

There is a number of important points about the account presented here which have consequences for loanword phonology. First, we have seen that in the Latinate stratum nouns become noun stems, but adjectives join stems which are not specified for any word class. In this sense it is a legitimate question whether SC has ever borrowed any Latinate adjectival stems. This has bearing for the common practice of creating borrowability scales. Second, the data analysed here originate from a contact in which the issue of the source language and the initial forms cannot be settled with much accuracy. For this reason the facts from the Latinate strata of the European languages are often glossed over. However, an approach which views loanword integration as a special type of lexicalisation shows the need to take these data as seriously as one-on-one language contacts of the type most European languages have with English nowadays.

More generally, we have seen that this is no ordinary grammar story. Words never enter the phonology, the morphology or the syntax of a language: they always enter the lexicon. Loanwords can therefore inform our 
research of the language faculty only if they are viewed from the perspective of the lexicon. Moreover, we have seen that loanword integration can diverge from derivations within a language to a sizable extent. Whereas in SC adjectives derived from nouns there are several adjectivising morphemes, whose occurrence is regulated by both phonology and semantics, Latinate adjectives use one suffix and one prosodic pattern. I have found very similar results in the integration of verbs and elsewhere (see Simonović in progress): integration patterns (and inter-language mappings) seem to be much simpler and more allomorphy-avoiding than the patterns within languages. This is one of the most important tasks for further research: now we have seen that inter-language patterns do not do the same kind of things as grammars, it is important to see whether they also operate on different type of elements than grammars.

In this contribution, I have attempted to show the need to view loanwords without the grammar bias - the tendency to reduce borrowing to mappings of the type directly comparable to grammars. I have also tried to show that the whole trajectory, from the initial surface form to the full lexical entry, needs to be taken into account. It is my hope that future research will interact with this contribution in ways that will enable further insights into the loanword-related processes and their place in the big picture of grammar and lexicon.

\section{References}

Arsenijević, Boban-Marko Simonović in progress. Postcyclic stress is interface stress.

Hammond, Michael 1989. Lexical stresses in macedonian and Polish. In: Phonology 6 : $19-38$.

Inkelas, Sharon - Draga Zec 1988. Serbo-Croatian pitch accent: The interaction of tone, stress and intonation. In: Language $64: 227-48$.

Kager, René to appear. Stress in windows: Language typology and factorial typology. To be published in: Lingua.

Kang, Yoonjung 2011. Loanword phonology. In: Marc van Oostendorp-Colin EwenElizabeth Hume - Keren Rice (eds): The Blackwell companion to phonology, 225882. Wiley-Blackwell, Malden MA \& Oxford.

Koneski, Blaze 1976. Gramatika na makedonskiot literaturen jazik [The grammar of Standard Macedonian]. Kultura, Skopje.

Rakić, Stanimir 2008. O mestu uzlaznih akcenata u srpskom jeziku-primer monomorfnih imenica [On the position of the rising accents in Serbian-the case of monomorphemic nouns]. In: Zbornik Matice srpske za filologiju i lingvistiku 51 : $75-86$. 
Simonović, Marko in progress. Lexicon immigration service-Prolegomena to a theory of loanword integration. Doctoral dissertation. Universiteit Utrecht.

Steriade, Donca 1997. Lexical conservatism. In: Sung-Yun Bak (ed.): SICOL 1997: Linguistics in the morning calm, 157-79. Hanshin Publishing House, Seoul.

Werle, Adam 2009. Word, phrase, and clitic prosody in Bosnian, Serbian, and Croatian. Doctoral dissertation, University of Massachusetts Amherst.

Zec, Draga 1999. Footed tones and tonal feet: Rhythmic constituency in a pitch-accent language. In: Phonology $16: 225-64$.

Zec, Draga - Elizabeth Zsiga 2010. Interaction of tone and stress in Standard Serbian: Phonological and phonetic evidence. In: Wayles Browne-Adam Cooper-Alison Fisher-Esra Kesici-Nikola Predolac-Draga Zec (eds): Formal approaches to Slavic linguistics 18: The Cornell Meeting 2008, 536-55. Michigan Slavic Publications, Ann Arbor. 